\title{
Intensive training in young athletes
}

\author{
N. Maffulli MD ${ }^{1}$ and E. Pintore $M^{2}$ \\ ${ }^{1}$ University of Naples, First Medical School, Department of Human Physiology, Section of Sports \\ Physiopathology, Naples, Italy \\ 2 Epsom District Hospital, Department of Orthopaedics, Epsom, Surrey, UK
}

\begin{abstract}
An increasing number of children take part in organized sporting activities, undergoing intensive training and high level competition from an early age. Although intensive training in children may foster health benefits, many are injured as a result of training, often quite seriously. This paper reviews some of the areas of research dealing with intensively trained young athletes, and focuses on physical, cardiovascular and muscular effects, sports injuries and psychological effects of intensive training. It is concluded that measures should be taken to modify present training and competition schemes to avoid the deleterious effects of intensive physical activity on these children.
\end{abstract}

Keywords: Intensive training, children, sports injuries

In the past few years, competitive sport participation has become an established feature of Western society ${ }^{1}$. Youngsters in their early teens may have already undergone intensive training and high level competition for several years in sports like gymnastics, swimming or tennis ${ }^{2}$. Rowley has reported that early participation of children in competitive training activities is due to the 'catch them young' philosophy $^{3}$, and to the belief that, to be able to achieve international acclaim, it is necessary to start intensive training before puberty.

The number of children taking part in competitive sports is so high that some medical bodies have issued guidelines regarding participation ${ }^{4,5}$. Although all the risks of injury in these youngsters are, at present, unknown ${ }^{6}$, an epidemic of sports injuries, as children change from free play to the stereotyped demands of the specialized patterns of movement imposed by a single sport, has been predicted $^{7,8}$.

The emphasis on intensive training and high level competition in a single sport begs the following questions:

Should young children participate in intensive training and high level competition?

Are children involved in intensive training at risk of injuries to their developing musculo-skeletal system?

Can psychological problems arise from intensive sports participation at a young age?

Address for correspondence: N. Maffulli, Institute of Child Health Respiratory and Anaesthetic Unit, Sports Medicine Laboratory, 30 Guildford Street, London WC1N 1EH, UK

(C) 1990 Butterworth-Heinemann Ltd 0306-3674/90/040237-03

\section{Physical, cardiovascular and muscular effects}

Increase in strength and endurance are an established feature of growth and development ${ }^{9}$ and of training ${ }^{10}$. The effects of physical training are difficult to separate from those of normal puberty'. Studies involving children have detected a wide range of results, from certain ill effects, such as growth retardation ${ }^{11}$, and no effects at all ${ }^{1,12-14}$. It is known that a certain amount of physical activity is required for normal growth ${ }^{1,11}$, but the minimum needed has not been identified, and the ill effects of intensive training have not been fully clarified ${ }^{1,9,11-14}$.

In girls, one of the most sensitive areas of research has been menarche and menstrual disorders. The age of achieving menarche, and the incidence and duration of menstrual disturbances in young athletes engaged in intensive training have been reviewed ${ }^{1,9}$. With few exceptions, menarche is delayed in athletes ${ }^{1}$. Moreover, female athletes engaged in intensive training show an increased frequency of menstrual irregularities ${ }^{12}$. The data dealing with this issue have not been convincingly researched. Factors that could influence the time of menarche, such as genetic influences or nutritional status, must be systematically controlled for meaningful conclusions to be drawn.

Also, the skeletal maturation of young male athletes engaged in cycling, rowing and ice hockey was followed from 12 to 15 years by Kotulan et al. ${ }^{13}$ who concluded that regular physical activity has no effects on the growth of young male athletes.

The question of athletic potential has been addressed. The response of a given athlete to a particular training regimen is due to an inherited genotype ${ }^{15}$. Only approximately $30 \%$ of the maximal oxygen uptake $\left(\mathrm{VO}_{2} \mathrm{max}\right)$ and maximal force and power of top class competitors can be accounted for by training.

Young athletes undergoing vigorous training were found to be taller and to have less body fat and higher $\mathrm{VO}_{2}$ max than sedentary controls ${ }^{16}$. In another study, 34 boys aged between 12 and 16 years old engaged in competitive middle and long distance running were compared with 56 controls not undergoing intensive training ${ }^{17}$. The runners had been training for 2 to 5 years, and had less body fat and lower resting heart rates. Statistically significant differences were only achieved between the 16 year olds. The young runners in this study also had larger heart volumes, 
and a higher $\mathrm{VO}_{2}$ max relative to body weight and respiratory capacity.

In another study, the effects of endurance and sprint training were studied on the vastus lateralis muscles of boys aged 16 and 17 years ${ }^{18}$. Endurance training resulted in a significant increase to type I and IIA fibre areas, together with increased activity of some of the enzymes of the Kreb's cycle. On the other hand, sprint-trained boys showed a significant increase in the activity of glycolytic enzymes.

Fewer controlled studies have dealt with the trainability of muscular strength in children. Pre- and post-pubescent children of both sexes can significantly increase their muscular strength by resistance training ${ }^{19,20}$. The traditional view ${ }^{19}$ in this respect is that the potential to develop strength is not at its maximum before puberty. Nevertheless, according to Pfeiffer and Francis, pre-pubescent children are likely to have a greater muscular strength trainability than older age groups ${ }^{21}$. When interpreting the effects of a strength training programme, one should consider that the natural increase in strength in boys reaches its maximum only approximately 1 year after the growth spurt, while in girls this occurs during the period of growth spurt itselP2.

Intensive training may result in staleness. There have been a number of reports of a fatigue syndrome in top class athletes. However, no controlled studies have been performed. Some possible important contributing factors to fatigue include an increased predisposition to viral infections, fatigue from overtraining or combination of physical and psychological fatigue analogous to the 'burn out syndrome' reported in other contexts ${ }^{10,23,24}$. Keast et al. have stated that sports mediated immune response alterations may play a major role in determining increased susceptibility to infections ${ }^{25}$.

\section{Sports injuries}

Some epidemiological studies have shown that between $3 \%$ and $11 \%$ of school-aged children are injured each year due to sports activity ${ }^{26,27}$. Physical characteristics can play a major role both in the choice of sport and on the pattern of injuries ${ }^{28}$. For example, joint laxity may result in a child's choice of gymnastics, but is associated with recurrent sprains and dislocation ${ }^{29}$.

During the growth spurt, adolescents are particularly vulnerable to injuries, partially due to imbalance in strength and flexibility'. The huge increases in participation, training and competition have resulted in children incurring injuries previously seen almost exclusively in adults ${ }^{30,31}$.

The skeletal system is extremely plastic in children and shows pronounced adaptive changes to intensive sports training ${ }^{32}$. The long-term effects on bone of participating in intensive training during the period of growth and development are still obscure. Low-intensity training can stimulate bone length, but high intensity training may inhibit $i^{33,34}$.

Sports injuries could result in damage to the growth mechanisms with subsequent life-lasting damage ${ }^{35}$. Physiological repetitive loading is indeed beneficial $^{36}$, but excessive efforts may result in serious injury of the weight-bearing joint surfaces ${ }^{37}$. Due to the presence of growing cartilage, and the process of growth itself, the skeletal system of a young athlete is more prone to specific types of injuries ${ }^{38}$. In addition, ligaments in children are two to five times stronger than the cartilage and bone of the epiphysial plate to which they are attached ${ }^{39,40}$. This results in a greater likelihood of fracture of the epiphysial-metaphysial junction rather than the ligamentous tears seen in adults.

Over-use injuries are characterized by chronic inflammation due to repeated microtrauma. Young athletes may develop one or more of a group of over-use injuries referred to as osteochondroses ${ }^{41}$. In some instances, an osteochondrosis involves degeneration of the centre of ossification where a major tendon attaches to the bone (an apophysis). Common sites are the posterior aspect of the calcaneus (Sever's disease), the tibial tubercle (Osgood-Schlatter disease), and the lower pole of the patella (SindingLarson-Johansson syndrome). The small carpal and tarsal bones may also be affected. Young athletes are therefore at risk of developing stress lesions to these susceptible growth areas. In childhood, compression stress fractures occur more commonly than the oblique type seen in adults ${ }^{42,43}$. Endurance training regimens are probably responsible for at least $60 \%$ of all over-use injuries sustained ${ }^{38}$ and could be avoided by appropriate changes in training.

In case of injury, the first therapeutic measure is rest $^{41}$. At high performance level, it is important to know whether an alteration of training regimen after an injury can maintain fitness and ensure rapid healing. Very little research has been performed in this area, although in one study that replaced endurance running with endurance cycling for 4 weeks it was observed that maximal aerobic power and submaximal running performance for moderately trained women runners was maintained ${ }^{44}$.

\section{Psychological effects}

Young competitors undergo increased stress and anxiety due to competition ${ }^{45}$ the outcome of which can be influenced by parents ${ }^{46}$, potentially leading to a greater incidence of aggression in the young athletes $^{47}$. These concerns have led to the extreme position of calling for a complete ban on high level competition in pre-adolescence because of the possible long term deleterious effects ${ }^{48}$. Detailed reviews of the psychological effects of intensive training on young athletes have recently been published ${ }^{3,14}$.

\section{Conclusions}

The physiological responses to training in children appear to be similar to those found in adults and, in the short term at least, seem beneficial. Definitive statements about the effects of intensive training on young athletes cannot yet be made. However, concerns about the physical and psychological injury remain, and it is likely that the age of the child and the particular sport should influence the type and intensity of training. 
Health professionals dealing with young athletes should be aware of these controversial issues. Children are not just adults in miniature, and they should not be assumed to be able of the same amount and quality of exertion as adults. Probably, it is safe to follow the ${ }^{\prime} 10 \%$ rule $^{\prime 49}$, which advocates progressing the intensity of any training programme no more than ten per cent a week.

Preparation and performance standards should take into account the chronological and biological age of the participants, as well as their physical and psychological immaturity. Adults dealing with high standard athletic children must not exploit the youngsters, but maintain the state of health of the children under their care, while helping them to improve their athletic performance. Better insight into different aspects of training is needed to avoid serious damage to children in high level competition. When planning a training programme, the physiological maturation process which the children undergo should be taken seriously into consideration. Time is needed for a growing child to incorporate his own body changes, and probably little room is left at this critical stage for developing speed, strength and resistance ${ }^{50}$.

\section{References}

1 Malina, R.M. Menarche in athletes: a synthesis and hypothesis Ann Hum Biol 1983, 10, 1-24

2 Malina, R.M., Meleski, B.W. and Shoup, R.F. Anthropometric, body composition, and maturity characteristics of selected school-age athletes Pediatr Clin North Am 1982, 29, 1305-1323

3 Rowley, S. The effects of intensive training on young athletes: A review of the research literature. Section 4: The effects of intensive training on the psychological and psychosocial development of the young athlete Sports Council, London, 1986

4 American Academy of Pediatrics. Competitive athletics for children of elementary school age Pediatrics 1981, 67, 927-928

5 American Academy of Pediatrics. Risks in long-distance running for children Phys Sportsmed 1982, 10, 82-86

6 Birrer, R.B. and Levine, R. Performance parameters in children and adolescent athletes Sports Med 987, 4, 211-227

7 Micheli, L.J. Overuse injuries in children's sport: The growth factor Orthop Clin North Am 1983, 14, 337-360

8 Stanitski, C.L. Pediatric sports injuries Adv Orthop Surg 1985, 9, 53-57

9 Malina, R.M. Human growth, maturation and regular physical activity Acta Med Aux 1983, 15, 5-27

10 Anonymous. Emotion and immunity Lancet 1985, 2, 33-34

11 Delmas, A. Intense physical activity among children and adolescents FIEP Bull 1982, 52 (2), 29-33

12 Bonen, A. and Keizer, H.A. Athletic menstrual cycle irregularities: Endocrine response to exercise and training Phys Sportsmed 1984, 8 (8), 78-90

13 Kotulan, J., Reznickova, M. and Placheta, Z. Exercise and growth. In: Placheta Z (ed) 'Youth and physical activity' 61-117, J.E. Purkyne University Medical Faculty, Brno, 1980

14 Rougier, G. Competitive sport and young children FIEP Bull 1982, 52, 39

15 Astrand, P.O. and Rodhal, K. Textbook of work physiology' (3rd Ed) McGraw-Hill Book Co, New York, 1986

16 Ekblom, B. Physical training in normal boys in adolescence Acta Paediatr Scan Suppl 1971, 217, 60-62

17 Sundberg, S. and Elovainio, R. Cardiorespiratory function in competitive endurance runners aged 12-16 years compared with ordinary boys Acta Paed Scand 1982, 71, 387-392

18 Fournier, M., Ricci, J., Taylor, A.W., Ferguson, R.J., Montpetit, R.R. and Chaitman, B.R. Skeletal muscle adaptations in adolescent boys: Sprint and endurance training and detraining Med Sci Sports Exer 1982, 14, 453-456
19 Nielsen, B., Nielsen, K., Behrendt-Hansen, M. and Asmussen, E. Training of 'functional' muscular strength in girls 7-19 years old In K. Berg and B. Eriksson (eds) 'Children and Exercise' IX, 68-69, University Park Press, Baltimore, 1980

20 Weltman, A. Weight training in prepubertal children. In: Bar-Or O (ed) 'Advance in Pediatric Sports Sciences' Vol. 3, Human Kinetics, Champaign, Illinois, 1988

21 Pfeiffer, R. and Francis, R.S. Effects of strength training on muscle development in prepubescent, pubescent, and postpubescent males Phys Sportsmed 1986, 14, 134-138

22 Beunen, G. Biological age in pediatric exercise research. In: Bar-Or O (ed) 'Advance in Pediatric Sports Sciences' Vol 3, Champaign, Illinois, Human Kinetics, 1988

23 Freudenberg, H.J. Staff burn out J Soc Issues 1974, 30, 159-165

24 Marshall, R.E. and Kasman, C. Burnout in the neonatal intensive care Pediatrics 1980, 65, 1161-1165

25 Keast, D., Cameron, K. and Morton, A.R. Exercise and the immune response Sports Med 1988, 5, 248-267

26 Gallagher, S.S., Finison, K., Guyer, B. and Goodenough, S. The incidence of injuries among 87,000 Massachusetts children and adolescents: Results of the 1980-81 Statewide Childhood Injury Prevention Program Surveillance System Am I Publ Health 1984, 8, 318-324

27 Zaricznyj, B., Shattuck, L.J.M., Mast, T.A., Robertson, R.V. and D'Elia, G. Sports-related injuries in school aged children Am I Sports Med 1980, 8, 318-324

28 Marshall, J.L. and Tischler, H.M. Screening for sports $N Y$ State J Med 1981, 9, 68-75

29 Lysens, R., Steverlynck, A. and Ostyn, M. The predictability of sports injuries Sports Med 1984, 1, 6-10

30 Hulkko, A. and Orava, S. Stress fractures in athletes Int J Sports Med 1987, 8, 221-226

31 Kvist, M., Kujala, U.M., Heinonen, O.J., Vuori, I.V., Aho, A.J., Pajulo, O. and Parvinen, T. Sports-related injuries in children Int J Sports Med 1989, 10, 81-86

32 Dalen, N. and Olson, K.E. Bone mineral content and physical activity Acta Orthop Scand 1974, 45, 170-174

33 Booth, F.W. and Gould, E.W. Effects of training and disuse on connective tissue Exerc Sports Sci Reo 1975, 3, 83-112

34 Tipton, C.M., Matthes, R.D. and Maynard, J.A. Influence of chronic exercise on rat bones Med Sci Sports 1972, 4, 55-58

35 Larson, R.L. and McMahon, R.O. The epiphysis and the childhood athlete J Am Med Ass 1966, 196, 607-612

36 Sedhom, B.B. and Wright, V. Is repetitive loading a cause of osteoarthritis? J Orthop Rheumatol 1988, 1, 79-87

37 Sowinski, J., Golebiewski, J. and Jozwiak, A. Minimum age limits for young marathon runners New Studies in Athletics $1986,4,91-100$

38 Wilkins, K.E. The uniqueness of the young athlete. Musculoskeltal injuries Am J Sports Med 1980, 5, 377-382

39 Cage, J.B. and Ivey, F.M. Intercondylar fracture of the femur in an adolescent athlete Phys Sportsmed 1983, 11 (6), 17-22

40 Schwab, S. A. Epiphyseal injuries in the growing athlete Can Med Ass J 1977, 117, 626-629

41 Kulund, D.N. 'The injured athlete' JB Lippincott Company, Philadelphia, 1982

42 Kozar, B. and Lord, R.M. Overuse injuries in the young athlete: reasons for concern Phys Sportsmed 1983, 11, 116-122

43 Paty, J.G. Jr and Swafford, D. Adolescent running injuries J Adol Health Care 1984, 5, 87-90

44 Moroz, D.E. and Houston, M.E. The effects of replacing endurance running with cycling in female runners Can J Sport Sci 1987, 12, 131-135

45 Smith, R.E. and Smoll, F.L. Psychological stress: a conceptual model and some intervention strategies in yough sport. In: Magill, R. and Smoll, F.L. (eds) 'Children in sport' Human Kinetics, Champaign, Illinois, 1982

46 Ogilvie, B. The child athlete: psychological implications of participation in sport Ann Am Acad Sci 1979, 445, 47-58

47 Sherif, M. and Sherif, C.W. 'Groups in harmony and tension' Harper, New York, 1953

48 Sayre, B.M. The need to ban competitive sport involving preadolescent kids Pediatrics 1975, 55, 564-568

49 Micheli, L.J. Lower extremity overuse injuries Acta Med Scand Suppl 1986, 711, 171-177

50 Wojtys, E.M. Sports injuries in the immature athlete Orthop Clin North Am 1987, 18, 689-708 